\title{
Effect of Rifampicin on the Pharmacokinetics of Lenvatinib in Healthy Adults
}

\author{
Robert C. Shumaker $\cdot$ Jagadeesh Aluri • \\ Jean Fan · Gresel Martinez • Gary A. Thompson • \\ Min Ren
}

Published online: 15 July 2014

(C) The Author(s) 2014. This article is published with open access at Springerlink.com

\begin{abstract}
Background and Objectives Lenvatinib is an oral, multitargeted tyrosine kinase inhibitor under clinical investigation in solid tumours. This study evaluated the influence of P-glycoprotein (P-gp) inhibition (single-dose rifampicin) and simultaneous cytochrome P450 3A4 (CYP3A4)/P-gp induction (multiple-dose rifampicin) on lenvatinib pharmacokinetics.

Methods This Phase I, single-centre, single-dose (lenvatinib mesylate $24 \mathrm{mg}$ ), open-label, sequential study enrolled 15 healthy volunteers. Three regimens were administered over three periods: Period (P) 1 (Days 1-8), P2 (Days 15-22) and P3 (Days 29-50), with a 14-day (first dose) and 28-day (second dose) washout period after lenvatinib mesylate administration (Day 1, Day 15 and Day 43). In P2, a single oral dose of rifampicin $(600 \mathrm{mg})$ was
\end{abstract}

J. Fan is now an employee of Boehringer-Ingelheim Pharmaceuticals, Inc., Ridgefield, CT, USA.

R. C. Shumaker · J. Aluri · J. Fan · G. Martinez · M. Ren

Eisai Inc., Woodcliff Lake, NJ, USA

e-mail: Jagadeesh_Aluri@eisai.com

J. Fan

e-mail: Jfan_123@yahoo.com

G. Martinez

e-mail: Gresel_Martinez@eisai.com

M. Ren

e-mail: Min_ren@eisai.com

R. C. Shumaker $(\bowtie)$

Clinical Pharmacology and Translational Medicine, Eisai Product Creation Systems, 300 Tice Boulevard, Woodcliff Lake,

NJ 07677, USA

e-mail: Robert_shumaker@eisai.com

G. A. Thompson

GA Thompson Consulting, West Chester, OH, USA

e-mail: gat.consulting@gmail.com coadministered with lenvatinib. In P3, rifampicin was administered daily $(600 \mathrm{mg}$ ) for 21 days (Days 29-49). Serial blood samples were collected, and plasma concentrations of total (protein bound + unbound) and free (unbound) lenvatinib and total metabolites (M1, M2, M3 and M5) were measured by validated high-performance liquid chromatography/tandem mass spectrometry.

Results Single-dose rifampicin (P-gp inhibition) increased area under the plasma concentration-time curve from time zero to infinity $\left(\mathrm{AUC}_{0-\infty}\right)$ of free and total lenvatinib by 32 and $31 \%$, respectively. Multiple-dose rifampicin (simultaneous P-gp and CYP3A4 induction) decreased lenvatinib $\mathrm{AUC}_{0-\infty}$ (total: $18 \%$; free: $9 \%$ ). Treatment-emergent adverse events were mild or moderate and occurred in 7 subjects $(47 \%)$.

Conclusion Lenvatinib exposure was increased by P-gp inhibition; however, based on free concentrations, simultaneous P-gp and CYP3A4 induction results met the prespecified bioequivalence $90 \%$ confidence interval. Overall, the magnitude of these changes was relatively small, and likely not clinically meaningful.

\section{Impact and Key Points}

Lenvatinib exposure was increased $\sim 30 \%$ by P-glycoprotein inhibition (single-dose rifampicin) while area under the plasma concentration-time curve (AUC) decreased 9-18\% and maximum plasma concentration $\left(C_{\max }\right)$ increased $0-9 \%$ with simultaneous cytochrome P450 3A4 (CYP3A4)/Pglycoprotein induction (multiple-dose rifampicin).

The magnitude of the changes in lenvatinib exposure was modest and therefore not likely to be clinically meaningful. 


\section{Introduction}

Tyrosine-kinase-mediated signalling of vascular endothelial growth factor receptor (VEGF), fibroblast growth factor (FGF) and platelet-derived growth factor (PDGF) pathways is involved in the regulation of apoptosis, cell proliferation, cellular metabolism and angiogenesis, and has been implicated in tumorigenesis and progression of multiple solid tumours [1]. Several tyrosine kinase inhibitors (TKIs) of these pathways are currently available or under investigation for the treatment of multiple malignancies [1].

Lenvatinib mesylate (i.e. lenvatinib) is an orally active, once-daily dosed TKI of VEGF receptors (R) 1-3, FGFR1, PDGFR- $\alpha$, ret proto-oncogene (RET) and v-kit HardyZuckerman 4 feline sarcoma viral oncogene homolog (KIT) $[2,3]$ and is currently being clinically evaluated in several solid tumour types. Phase I and II studies have demonstrated antitumour activity and manageable toxicity for lenvatinib mesylate as a single agent at a maximum tolerated dose of $25 \mathrm{mg} /$ day [4-6].

Lenvatinib pharmacokinetics have been assessed in humans following both single- and multiple-dose oral administration. Lenvatinib mesylate is rapidly absorbed following a single dose, with the observed time the maximum concentration occurred $\left(t_{\max }\right)$ typically ranging between 1 and $4 \mathrm{~h}$ [7]. For doses between 0.8 and $32 \mathrm{mg}$, the apparent oral clearance of lenvatinib ranges from 4.2 to $7.1 \mathrm{~L} / \mathrm{h}$, while the apparent terminal volume of distribution (uncorrected for bioavailability) ranges from 50.5 to $163 \mathrm{~L}$. The contribution of renal excretion to oral clearance, based on mass balance, is minimal $(\sim 1-2 \%)$. The terminal exponential half-life $\left(t_{1 / 2}\right)$ is $\sim 28 \mathrm{~h}$ (Eisai data on file). Upon single and multiple dosing, both area under the plasma concentration vs time curve (AUC) and maximum plasma concentration $\left(C_{\max }\right)$ of total (protein boun$\mathrm{d}+$ unbound) lenvatinib increased proportionally with dose $[4,5]$. For doses ranging from 12 to $32 \mathrm{mg}$ once daily, the mean accumulation index based on AUC ranged from 0.96 to 1.28 (Eisai data on file).

In vitro and in vivo studies have demonstrated that lenvatinib is metabolized in both liver and kidney, and it is primarily excreted directly in bile $[8,9]$. In a radiolabelled human mass balance study examining total lenvatinib (parent + metabolites), $\sim 64 \%$ of the radioactivity was recovered in the faeces and $\sim 25 \%$ in urine, with only $2.5 \%$ of the administered lenvatinib dose recovered intact [8]. In human liver microsomes, the demethylated metabolite of lenvatinib (M2) was identified as the major metabolite. Cytochrome P450 (CYP) 3A4 was the predominant $(>80 \%)$ CYP isoform involved in the CYPmediated metabolism of lenvatinib, and lenvatinib does not appear to induce or inhibit CYPs (Eisai data on file). In addition, lenvatinib is also a substrate for the multidrug resistance 1 (MDR1) transport protein (P-glycoprotein [Pgp]) and weakly inhibits MDR1 transport (Eisai data on file). Lenvatinib plasma protein binding has previously been assessed in vitro using human plasma and ultrafiltration, the results of which indicate that plasma protein binding is high (range 97.9-98.6\%), is concentration independent over the range of $0.3-30 \mu \mathrm{g} / \mathrm{mL}$ and is primarily bound to albumin (Eisai data on file). Therefore, both free (unbound) and total (protein bound + unbound) lenvatinib were analysed in this study.

Rifampicin, an antibiotic derivative of rifamycin B, is a strong inducer of P-gp and CYP3A4 upon multiple dosing, but inhibits gut $\mathrm{P}$-gp-mediated transport when only a single dose is administered [10]. At therapeutic doses, rifampicin significantly alters plasma concentrations of CYP3A4 substrates [11-13]. Hence, rifampicin is routinely used to evaluate the potential for drug interactions involving CYP3A4 induction and P-gp induction/inhibition mechanisms with pharmaceutical products including TKIs [14-18].

Since lenvatinib appears to metabolize $>25 \%$ via CYP3A4 based on an in vitro metabolic study and also appears to be a P-gp substrate, this study evaluated the influence of P-gp inhibition (single-dose rifampicin) and simultaneous CYP3A4/P-gp induction (multiple-dose rifampicin) on lenvatinib pharmacokinetics, which is consistent with the Food and Drug Administration Division of Drug Information guidance [15].

\section{Methods}

\subsection{Study Design}

This was a single-centre, single-dose, open-label, sequential, 3-period study. The study was conducted in accordance with the International Conference on Harmonisation guidelines and in compliance with local and national regulations. The protocol and the informed consent document received approval from an independent institutional review board (Independent Investigational Review Board, Plantation, FL, USA) before any subjects were enrolled. All subjects provided written informed consent.

\subsection{Subjects}

Healthy, nonsmoking male or female (not pregnant or lactating) adults $18-55$ years of age with a body mass index $\geq 18$ to $30 \mathrm{~kg} / \mathrm{m}^{2}$ were enrolled. Subjects with clinically significant systemic diseases or abnormalities, or a known history of any gastrointestinal surgery that could 
impact the pharmacokinetics of lenvatinib, were excluded. Additional exclusion criteria included clinically significant illness within 8 weeks of lenvatinib mesylate administration or infection within 4 weeks, clinically significant electrocardiogram (ECG) abnormality, QTc interval $>450 \mathrm{~ms}$, history of drug or food allergies or current seasonal allergy, use of over-the-counter medications within 2 weeks, history of drug or alcohol misuse, positive test for hepatitis $\mathrm{A}, \mathrm{B}$, or $\mathrm{C}$, or human immunodeficiency virus, recent weight change $>10 \%$ or participation in vigorous exercise, or haemoglobin $<12.0 \mathrm{~g} / \mathrm{dL}$. Individuals who had taken prescription drugs including CYP3A4 inhibitors/inducers within 4 weeks of study drug administration were excluded from participating. Subjects who had taken dietary supplements, herbal preparations or other foods or beverages that may affect various drug metabolizing enzymes and transporters (e.g. alcohol, grapefruit, vegetables from the mustard green family and charbroiled meats) within 2 weeks prior to dosing, or caffeine-containing products within $72 \mathrm{~h}$ before dosing, were excluded from the study. In addition, since rifampicin is known to cause failure of hormonal contraceptives (e.g. oral contraceptive, contraceptive implant, hormone-releasing intrauterine device) [19], women of childbearing potential and men who were partners of women of childbearing potential agreed to use other contraceptive methods during the study period and for $\geq 30$ days after the last dose of study drug.

\subsection{Treatments}

Subjects were administered three regimens over three periods: Period 1 (Days 1-8), Period 2 (Days 15-22) and Period 3 (Days 29-50) with a 14-day washout after the first study drug dose and a 28-day washout after the second study drug dose. Subjects received a single oral dose of lenvatinib mesylate (Eisai, Inc., Woodcliff Lake, NJ, USA) $24 \mathrm{mg}(1 \times 4-\mathrm{mg}$ and $2 \times 10-\mathrm{mg}$ capsules; dose sizes are for the anhydrous free base) on Day 1 (Period 1), Day 15 (Period 2) and Day 43 (Period 3). In Period 2 on Day 15, subjects received a single oral dose of rifampicin (Epic Pharma, LLC, Laurelton, NY, USA) 600 mg $(2 \times 300-\mathrm{mg}$ capsules) coadministered with lenvatinib mesylate. In Period 3, subjects received rifampicin $600 \mathrm{mg}$ orally daily for 21 days (Days 29-49) with lenvatinib mesylate and rifampicin coadministered on Day 43. Day 50 was an offtreatment visit.

Lenvatinib mesylate was administered after a 10-h fast; subjects were not allowed to eat for $4 \mathrm{~h}$ following lenvatinib mesylate dosing and were required to maintain an upright position. Both lenvatinib mesylate and rifampicin were administered with 8 ounces $(240 \mathrm{~mL})$ of water. On other days, rifampicin was administered $1 \mathrm{~h}$ prior to breakfast. Subjects were not to engage in heavy exercise (e.g. marathon running, weight lifting) from at least 2 weeks prior to dosing until the end of the study.

\subsection{Blood Sampling}

Serial blood samples in heparinized tubes for lenvatinib and metabolite analysis were collected predose and at 0.5 , $1,2,3,4,8,12,16$ and $24 \mathrm{~h}$ after dosing, and then every 24-h until $168 \mathrm{~h}$ postdose following lenvatinib doses on Days 1, 15 and 43 .

\subsection{Bioanalytical Methods}

Plasma concentrations of total (unbound + protein bound) and free (unbound) lenvatinib and total metabolites (M1, M2, M3 and M5) were measured by validated highperformance liquid chromatography/tandem mass spectrometry methods [20]. Linear ranges of the assays were as follows: (1) free unbound lenvatinib, $5-2,000 \mathrm{pg} / \mathrm{mL}$; (2) total (bound + unbound) lenvatinib, $0.25-250 \mathrm{ng} / \mathrm{mL}$; (3) metabolites, $0.25-50 \mathrm{ng} / \mathrm{mL}$. Interday precision (percent coefficient of variation [CV]) ranged from 4.50 to 7.20 and interday accuracy (\% bias) ranged from -9.40 to 6.00 for total lenvatinib. For free lenvatinib, interday precision $(\% \mathrm{CV})$ ranged from 2.90 to 6.30 and interday accuracy (\% bias) ranged from -1.70 to 1.70 . Across all metabolites, interday accuracy ranged from -5.10 to 12.4 and interday precision ranged from 2.90 to 8.70 . Interference checks for rifampicin were tested with no impact on the quantitation of lenvatinib and its metabolites.

\subsection{Pharmacokinetic Methods}

Pharmacokinetic parameters were calculated using a noncompartmental pharmacokinetic analysis with WinNonlin ${ }^{\circledR}$ version 6.2 (Pharsight Corporation, Mountain View, CA, USA) and Microsoft ${ }^{\circledR}$ Excel version 2010 [21, 22]. The terminal exponential rate constant $(\lambda \mathrm{z})$ was determined using linear least squares regression of the terminal phase of the log concentration-time profile. The $t_{1 / 2}$ was obtained as $0.693 / \lambda \mathrm{z}$. The $\mathrm{AUC}_{\text {last }}$ was determined up to the last observed quantifiable concentration, using the linear-up and log-down trapezoidal rule. The AUC from time zero to infinity $\left(\mathrm{AUC}_{0_{-} \infty}\right)$ was the sum of $\mathrm{AUC}_{\text {last }}$ and the extrapolated AUC $\left(\mathrm{AUC}_{\mathrm{ext}}\right)$, which was obtained based on the last observed quantifiable plasma concentration and the terminal exponential rate constant. $C_{\max }$ and $t_{\max }$ were determined from visual inspection of concentration-time data. Lag time was determined as the time prior to the first quantifiable concentration. Apparent oral clearance (CL/F) and apparent terminal volume of distribution $(\mathrm{Vz} / \mathrm{F})$ were determined using standard equations. For parameter calculations, measurements that were below the lower limit of 
quantitation (LLOQ) before the occurrence of a measurable concentration were treated as zero; values below the LLOQ at the end of the curve were considered missing.

\subsection{Safety Assessments}

Adverse events (AEs) were monitored on a daily basis and graded by the investigator on a three-point scale (mild, moderate, severe) in terms of severity and causality to the study drug. Vital signs (blood pressure, heart rate, body temperature, respiratory rate) were recorded prior to pharmacokinetic blood sample collection. Additional safety assessments, including clinical laboratory testing, 12-lead ECGs and physical examinations, were made during baseline periods, before each dose and prior to discharge.

\subsection{Statistics}

Statistical programming and analyses were performed using SAS $^{\circledR}$ software, version 9.2 (SAS Institute Inc., Cary, NC, USA). Assuming an intrasubject standard deviation of log-transformed $C_{\max }$ of lenvatinib of 0.44 and using a 2-sided test with an alpha of 0.05 , a sample size of 11 completing subjects would provide $91 \%$ power to detect a twofold change in $C_{\max }$. Based on clinical experience, 15 subjects were enrolled with the intent to complete 11 subjects. A linear mixed-effects model with log-transformed pharmacokinetic parameters as response was used to estimate the ratios of geometric means and associated two-sided $90 \%$ confidence intervals (CIs) for AUC and $C_{\max }$ [23]. Separate models were constructed individually for the two comparisons: coadministration of lenvatinib mesylate with either single- or multiple-dose rifampicin (Period 2 and Period 3, respectively) versus lenvatinib mesylate alone (Period 1), and the ratios of geometric means and associated twosided $90 \%$ CIs were estimated for $C_{\max }, \mathrm{AUC}_{\text {last }}$ and $\mathrm{AUC}_{0-\infty}$ in each comparison for both free and total lenvatinib. If the $90 \%$ CIs fell within the range of $80-125 \%$, then the test was considered to be bioequivalent to the reference and an absence of drug interaction could be concluded. Other pharmacokinetic parameters and plasma lenvatinib concentrations by time point were summarized using descriptive statistics.

Safety parameters were evaluated descriptively for all subjects who received study drug and had at least one safety assessment postdose. AEs were classified into standardized terminology using the Medical Dictionary for Regulatory Activities (version 9 or higher). Other parameters, including baseline subject characteristics, were also evaluated descriptively.

\section{Results}

\subsection{Disposition and Demographics}

Fifteen subjects were enrolled and all completed Periods 1 and 2. One subject discontinued during Period 3 due to AEs. The majority of enrolled subjects were male (73\%) and white $(67 \%)$ with a median age of 31.0 years (range 20-49 years) (Table 1 ).

\subsection{Pharmacokinetics}

For each of the three study periods, lenvatinib was rapidly absorbed and $C_{\max }$ was achieved at a median $t_{\max }$ of 2-2.5 h (Table 2). Both total (protein bound + unbound) and free lenvatinib plasma concentration-time profiles appeared biphasic across the three treatments following achievement of the peak concentration (total lenvatinib $C_{\text {max }}$ : lenvatinib alone, $274 \mathrm{ng} / \mathrm{mL}$ (CV: $36.2 \%$ ); with single-dose rifampicin, $365 \mathrm{ng} / \mathrm{mL}$ (CV: $35.2 \%)$; with multiple-dose rifampicin, $275 \mathrm{ng} / \mathrm{mL}(\mathrm{CV}: 28.6 \%)$ and free lenvatinib $C_{\max }$ : lenvatinib alone, $5.69 \mathrm{ng} / \mathrm{mL}(\mathrm{CV}$ : $28.1 \%$ ); with single-dose rifampicin, $7.40 \mathrm{ng} / \mathrm{mL}$ (CV: $25.8 \%$ ); with multiple-dose rifampicin, $6.25 \mathrm{ng} / \mathrm{mL}$ (CV: $20.8 \%$ ); Fig. 1). The percentages of $\mathrm{AUC}_{0-\infty}$ extrapolated for free and total lenvatinib were generally $<2 \%$.

\subsection{Lenvatinib with Single-Dose Rifampicin}

Exposure to free lenvatinib was $32 \%$ higher and total lenvatinib concentration was $31 \%$ greater, based on $\mathrm{AUC}_{0-\infty}$, when lenvatinib mesylate was coadministered with a single dose of rifampicin compared with only lenvatinib mesylate. $C_{\max }$ estimates of both free and total lenvatinib were approximately 30 and $33 \%$ greater,

Table 1 Subject demographics and baseline characteristics $(N=15)$

\begin{tabular}{lc}
\hline Characteristic & Value \\
\hline Age, years & \\
Mean (SD) & $34.3(10.10)$ \\
Median (range) & $31.0(20-49)$ \\
Sex, $n(\%)$ & \\
Male & $11(73.3)$ \\
Female & $4(26.7)$ \\
Race, $n(\%)$ & \\
White & $10(66.7)$ \\
Black/African American & $3(20.0)$ \\
Other & $2(13.3)$ \\
BMI, kg/m ${ }^{2}$, median (range) & $24.24(19.1-29.0)$ \\
\hline
\end{tabular}

$B M I$ body mass index, $S D$ standard deviation 
Table 2 Pharmacokinetic parameters of lenvatinib mesylate $24 \mathrm{mg}$ administered alone or in combination with single-dose rifampicin (600 mg) or following multiple doses $(600 \mathrm{mg} /$ day $)$ of rifampicin

\begin{tabular}{|c|c|c|c|}
\hline Parameter & $\begin{array}{l}\text { Lenvatinib mesylate alone } \\
{[\mathrm{A}] n=15}\end{array}$ & $\begin{array}{l}\text { Lenvatinib mesylate }+ \text { single-dose } \\
\text { rifampicin }[\mathrm{B}] n=15\end{array}$ & $\begin{array}{l}\text { Lenvatinib mesylate }+ \text { multiple-dose } \\
\text { rifampicin }[\mathrm{C}] n=14\end{array}$ \\
\hline \multicolumn{4}{|l|}{ Free lenvatinib } \\
\hline$C_{\max }(\mathrm{ng} / \mathrm{mL})$ & $5.69(28.1)$ & $7.40(25.8)$ & $6.25(20.8)$ \\
\hline GLSMR (90 \% CI) & - & B/A: 1.299 (1.134-1.488) & C/A: 1.087 (0.973-1.214) \\
\hline $\mathrm{AUC}_{\text {last }}(\mathrm{ng} \cdot \mathrm{h} / \mathrm{mL})$ & $58.8(33.7)$ & $77.7(23.3)$ & $55.0(30.8)$ \\
\hline GLSMR (90 \% CI) & - & B/A: $1.322(1.160-1.507)$ & C/A: 0.908 (0.832-0.992) \\
\hline $\mathrm{AUC}_{0-\infty}(\mathrm{ng} \cdot \mathrm{h} / \mathrm{mL})$ & $59.4(33.3)$ & $78.2(23.1)$ & $55.5(30.5)$ \\
\hline GLSMR (90 \% CI) & - & B/A: 1.318 (1.158-1.500) & C/A: 0.907 (0.832-0.988) \\
\hline $\mathrm{AUC}_{0-24}(\mathrm{ng} \cdot \mathrm{h} / \mathrm{mL})$ & $49.9(32.5)$ & $66.6(21.7)$ & $48.8(27.4)$ \\
\hline$t_{\max }(\mathrm{h})^{\mathrm{a}}$ & $2.05(2.00-4.00)$ & $2.02(1.00-8.00)$ & $2.54(1.00-8.00)$ \\
\hline$t_{\operatorname{lag}}(\mathrm{h})^{\mathrm{a}}$ & $0.00(0.00-0.50)$ & $0.00(0.00-0.53)$ & $0.00(0.00-0.50)$ \\
\hline$t_{1 / 2}(\mathrm{~h})$ & $18.1(43.4)$ & $16.2(30.6)$ & $14.3(23.4)$ \\
\hline CL/F (L/h) & $404(33.4)$ & $307(23.1)$ & $433(30.5)$ \\
\hline $\mathrm{Vz} / \mathrm{F}(\mathrm{L})$ & $10,600(44.4)$ & $7,180(37.6)$ & $8,950(36.9)$ \\
\hline \multicolumn{4}{|l|}{ Total lenvatinib } \\
\hline$C_{\max }(\mathrm{ng} / \mathrm{mL})$ & $274(36.2)$ & $365(35.2)$ & $275(28.6)$ \\
\hline GLSMR (90 \% CI) & - & B/A: 1.334 (1.126-1.581) & C/A: 1.004 (0.831-1.212) \\
\hline $\mathrm{AUC}_{\text {last }}(\mathrm{ng} \cdot \mathrm{h} / \mathrm{mL})$ & $2,350(24.4)$ & $3,080(22.8)$ & $1,940(27.1)$ \\
\hline GLSMR $(90 \%$ CI) & - & B/A: 1.308 (1.229-1.392) & C/A: 0.818 (0.733-0.914) \\
\hline $\mathrm{AUC}_{0-\infty}(\mathrm{ng} \cdot \mathrm{h} / \mathrm{mL})$ & $2,370(24.2)$ & $3,090(22.7)$ & $1,950(27.1)$ \\
\hline GLSMR $(90 \%$ CI) & - & B/A: 1.306 (1.227-1.390) & C/A: $0.818(0.733-0.913)$ \\
\hline $\mathrm{AUC}_{0-24}(\mathrm{ng} \cdot \mathrm{h} / \mathrm{mL})$ & $2,000(25.2)$ & $2,690(22.9)$ & $1,760(27.5)$ \\
\hline$t_{\max }(\mathrm{h})^{\mathrm{a}}$ & $2.03(2.00-4.00)$ & $2.00(1.00-3.00)$ & $2.54(1.00-4.00)$ \\
\hline$t_{\text {lag }}(\mathrm{h})^{\mathrm{a}}$ & $0.00(0.00-0.50)$ & $0.00(0.00-0.50)$ & $0.00(0.00-0.50)$ \\
\hline$t_{1 / 2}(\mathrm{~h})$ & $22.0(34.1)$ & $21.5(39.1)$ & $18.2(42.0)$ \\
\hline $\mathrm{CL} / \mathrm{F}(\mathrm{L} / \mathrm{h})$ & $10.1(24.3)$ & $7.77(22.8)$ & $12.3(27.1)$ \\
\hline $\mathrm{Vz} / \mathrm{F}(\mathrm{L})$ & $322(39.1)$ & $240(42.7)$ & $324(42.1)$ \\
\hline
\end{tabular}

Values are geometric mean $(\% \mathrm{CV})$ unless otherwise noted

$A U C_{0-24}$ area under the plasma concentration-time curve from time zero to $24 \mathrm{~h}, A U C_{0-\infty} \mathrm{AUC}$ from time zero to infinity, $A U C_{l a s t} \mathrm{AUC}$ from time zero to the last measurable concentration, $C I$ confidence interval, $C L / F$ oral clearance of the drug, $C_{\max }$ maximum observed plasma concentration, GLSMR geometric least squares means ratio, $t_{1 / 2}$ terminal exponential half-life, $t_{\text {lag }}$ lag time: time delay between drug administration and onset of drug absorption, $t_{\max }$ time to reach maximum concentration after drug administration, $V z / F$ terminal volume of distribution, $\% C V$ percent coefficient of variation of geometric mean

a Median (range)

respectively, when lenvatinib mesylate was coadministered with a single dose of rifampicin. The $90 \%$ CIs of the geometric least squares means ratios for $C_{\max }$ and $\mathrm{AUC}_{0-\infty}$ were above the upper CI boundary of the prespecified bioequivalence interval of 80-125\% for both total and free lenvatinib following a single rifampicin dose (Table 2; Fig. 2). There were decreases in both $\mathrm{Vz} / \mathrm{F}$ (free: $32 \%$; total: $25 \%$ ) and CL/F (free: $24 \%$; total: $23 \%$ ) for lenvatinib mesylate with single-dose rifampicin compared with lenvatinib mesylate without rifampicin (Table 2). The $t_{1 / 2}$ of free lenvatinib decreased by $2 \mathrm{~h}$ (to $\sim 16 \mathrm{~h}$ ), while that of total lenvatinib decreased by $0.5 \mathrm{~h}$ (to $21.5 \mathrm{~h}$ ) with single-dose rifampicin.

\subsection{Lenvatinib with Multiple-Dose Rifampicin}

Exposure to free lenvatinib was $\sim 9 \%$ lower and total lenvatinib concentration was $\sim 18 \%$ lower, based on $\mathrm{AUC}_{0-\infty}$ following multiple doses of rifampicin compared with lenvatinib mesylate alone. $C_{\max }$ estimates of free lenvatinib were $8.7 \%$ higher after multiple doses of rifampicin, whereas total lenvatinib $C_{\max }$ remained unchanged. The lower bound for the $90 \%$ CIs for $\mathrm{AUC}_{0-\infty}$ for total lenvatinib was $73.3 \%$, below the lower CI boundary of bioequivalence. However, the $90 \% \mathrm{CI}$ for total $C_{\max }$ was within this interval. The $90 \%$ CIs of the geometric least squares means ratios for $C_{\max }$ and $\mathrm{AUC}_{0-\infty}$ for free 

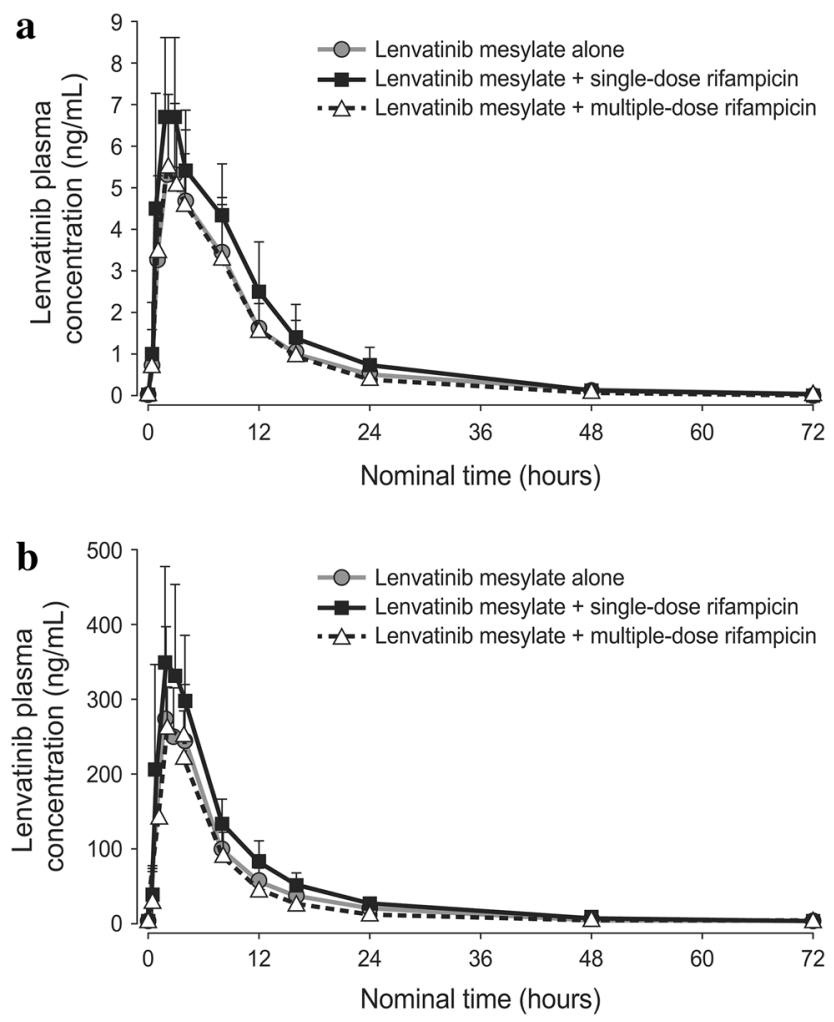

Fig. 1 Mean plasma concentration (+standard deviation) of a free (unbound) lenvatinib and $\mathbf{b}$ total (protein-bound + unbound) lenvatinib vs time following oral administration of lenvatinib mesylate $(24 \mathrm{mg})$ alone, lenvatinib mesylate $(24 \mathrm{mg})$ with a single dose of rifampicin $(600 \mathrm{mg})$ or lenvatinib mesylate $(24 \mathrm{mg})$ plus multiple doses of rifampicin $(600 \mathrm{mg} /$ day $)$

lenvatinib in the rifampicin multidose group were within the prespecified bioequivalence interval.

$\mathrm{Vz} / \mathrm{F}$ for free lenvatinib decreased approximately $16 \%$ following multidose treatment, whereas $\mathrm{CL} / \mathrm{F}$ increased $10 \%$. Total lenvatinib Vz/F remained effectively unchanged following multiple doses of rifampicin with a $22 \%$ increase in $\mathrm{CL} / \mathrm{F}$. The mean $t_{1 / 2}$ of both free and total lenvatinib both decreased $\sim 4 \mathrm{~h}$ (free: $\sim 14 \mathrm{~h}$; total: $\sim 18 \mathrm{~h}$ ) after multiple doses of rifampicin.

Fig. 2 Box plots of free (unbound) and total (protein-bound + unbound) lenvatinib $\mathrm{AUC}_{0-\infty}$ and $C_{\max }$ under conditions of lenvatinib mesylate $(24 \mathrm{mg})$ administered alone or in combination with either a single dose $(600 \mathrm{mg})$ or multiple doses of rifampicin $(600 \mathrm{mg} /$ day $)$. Free lenvatinib: a $\mathrm{AUC}_{0-\infty}$ and $\mathbf{b} C_{\max }$; total lenvatinib: c $\mathrm{AUC}_{0-\infty}$ and $\mathbf{d} C_{\max }$. Treatment median is represented by the horizontal line in the box, the upper and lower shaded areas represent 25th and 75th percentiles, and the vertical lines extend to the treatment minimum and maximum values, excluding outliers. Plotted points (asterisks) beyond the whiskers are outliers, defined as values outside of $1.5 \times$ the interquartile range. $A U C_{0-\infty}$ area under the plasma concentrationtime curve from time zero to infinity, $C_{\max }$ maximum observed plasma concentration
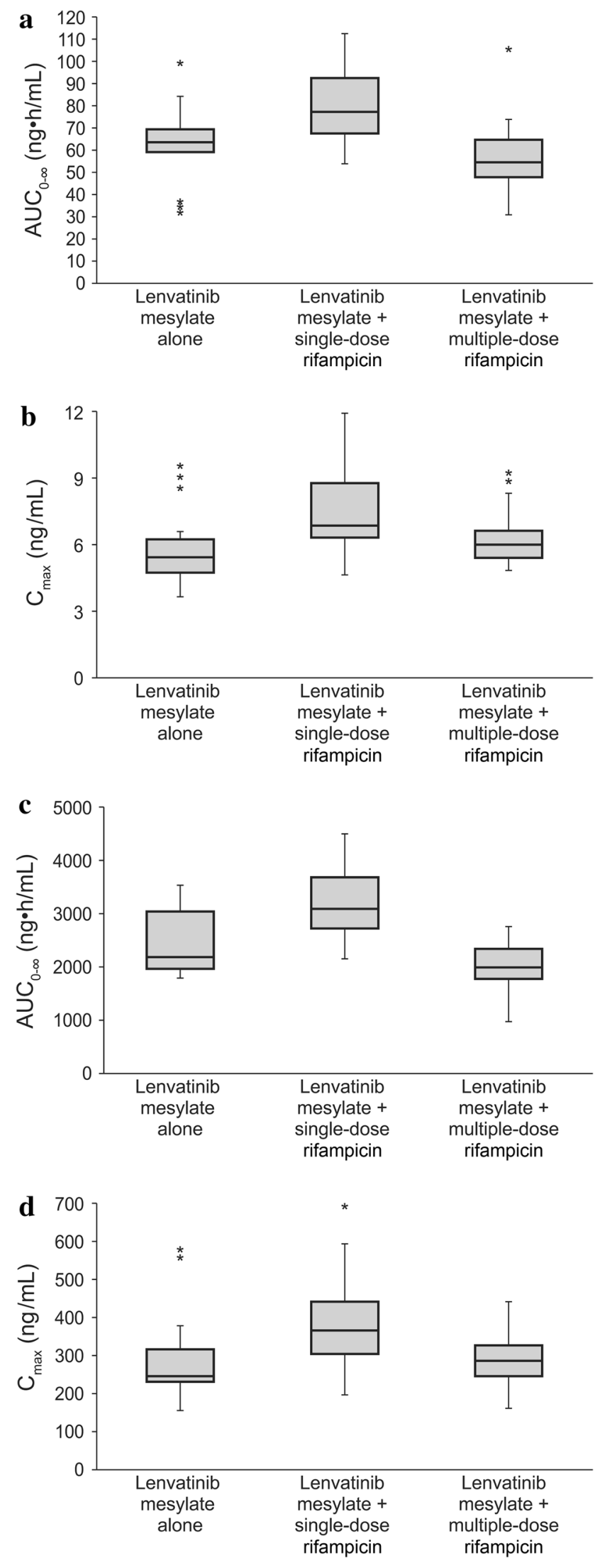
Table 3 Pharmacokinetic parameters for total metabolites of lenvatinib

\begin{tabular}{|c|c|c|c|c|}
\hline Metabolite & Parameter & $\begin{array}{l}\text { Lenvatinib mesylate } 24 \mathrm{mg} \\
\text { alone } n=15\end{array}$ & $\begin{array}{l}\text { Lenvatinib mesylate } 24 \mathrm{mg}+ \\
\text { single-dose rifampicin } n=15\end{array}$ & $\begin{array}{l}\text { Lenvatinib mesylate } 24 \mathrm{mg}+ \\
\text { multiple-dose rifampicin } n=14\end{array}$ \\
\hline \multirow[t]{5}{*}{ M1 } & $C_{\max }(\mathrm{ng} / \mathrm{mL})$ & ND & $0.304(6.28)^{\mathrm{a}}$ & $0.330(27.9)^{\mathrm{b}}$ \\
\hline & $\operatorname{AUC}_{0-\infty}(\mathrm{ng} \cdot \mathrm{h} / \mathrm{mL})$ & ND & NR & $\mathrm{NR}$ \\
\hline & $\mathrm{AUC}_{\text {last }}(\mathrm{ng} \cdot \mathrm{h} / \mathrm{mL})$ & ND & $0.078(3.46)^{\mathrm{a}}$ & $0.441(109)^{\mathrm{b}}$ \\
\hline & $t_{\max }(\mathrm{h})^{\mathrm{c}}$ & ND & $1.01(1.00-1.02)^{\mathrm{a}}$ & $2.05(1.00-3.00)^{\mathrm{b}}$ \\
\hline & $t_{\text {lag }}(\mathrm{h})^{\mathrm{c}}$ & ND & $0.50(0.50-0.50)^{\mathrm{a}}$ & $1.00(0.50-1.00)^{\mathrm{b}}$ \\
\hline \multirow[t]{5}{*}{ M2 } & $C_{\max }(\mathrm{ng} / \mathrm{mL})$ & $0.951(71.5)$ & $4.09(49.8)$ & $2.78(50.8)$ \\
\hline & $\operatorname{AUC}_{0-\infty}(\mathrm{ng} \cdot \mathrm{h} / \mathrm{mL})$ & $9.13(66.3)^{\mathrm{d}}$ & $24.1(33.8)$ & $13.4(34.4)^{\mathrm{e}}$ \\
\hline & $\mathrm{AUC}_{\text {last }}(\mathrm{ng} \cdot \mathrm{h} / \mathrm{mL})$ & $3.31(132)$ & $21.8(36.0)$ & $10.3(55.3)$ \\
\hline & $t_{\max }(\mathrm{h})^{\mathrm{c}}$ & $2.00(1.00-3.00)$ & $2.00(1.00-3.02)$ & $2.00(1.00-4.00)$ \\
\hline & $t_{\text {lag }}(\mathrm{h})^{\mathrm{c}}$ & $0.50(0.00-1.00)$ & $0.50(0.00-1.00)$ & $0.50(0.00-1.00)$ \\
\hline \multirow[t]{5}{*}{ M3 } & $C_{\max }(\mathrm{ng} / \mathrm{mL})$ & ND & $0.278(15.1)^{\mathrm{a}}$ & $0.289(9.19)^{f}$ \\
\hline & $\mathrm{AUC}_{0-\infty}(\mathrm{ng} \cdot \mathrm{h} / \mathrm{mL})$ & ND & NR & NR \\
\hline & $\mathrm{AUC}_{\text {last }}(\mathrm{ng} \cdot \mathrm{h} / \mathrm{mL})$ & ND & $0.246(102)^{\mathrm{a}}$ & $0.343(107)^{\mathrm{f}}$ \\
\hline & $t_{\max }(\mathrm{h})^{\mathrm{c}}$ & ND & $3.54(3.08-4.00)^{\mathrm{a}}$ & $2.07(2.00-4.00)^{\mathrm{f}}$ \\
\hline & $t_{\text {lag }}(\mathrm{h})^{\mathrm{c}}$ & ND & $2.01(2.00-2.02)^{\mathrm{a}}$ & $1.00(1.00-3.00)^{\mathrm{f}}$ \\
\hline \multirow[t]{5}{*}{ M5 } & $C_{\max }(\mathrm{ng} / \mathrm{mL})$ & $0.310(25.8)^{\mathrm{d}}$ & $0.375(38.3)^{\mathrm{g}}$ & $0.357(32.4)^{\mathrm{b}}$ \\
\hline & $\mathrm{AUC}_{0-\infty}(\mathrm{ng} \cdot \mathrm{h} / \mathrm{mL})$ & NR & NR & NR \\
\hline & $\mathrm{AUC}_{\text {last }}(\mathrm{ng} \cdot \mathrm{h} / \mathrm{mL})$ & $0.213(136)^{\mathrm{d}}$ & $0.557(117)^{\mathrm{g}}$ & $0.412(148)^{\mathrm{b}}$ \\
\hline & $t_{\max }(\mathrm{h})^{\mathrm{c}}$ & $2.52(1.00-4.00)^{\mathrm{d}}$ & $3.00(1.00-4.00)^{\mathrm{g}}$ & $2.00(1.00-4.00)^{\mathrm{b}}$ \\
\hline & $t_{\text {lag }}(\mathrm{h})^{\mathrm{c}}$ & $1.01(0.50-3.00)^{\mathrm{d}}$ & $1.00(0.50-3.00)^{\mathrm{g}}$ & $1.00(0.50-3.00)^{\mathrm{b}}$ \\
\hline
\end{tabular}

Values are geometric mean $(\% \mathrm{CV})$ unless otherwise noted

$A U C_{\text {last }}$ area under the plasma concentration-time profile from time zero to the last measurable concentration, $A U C_{0-\infty}$ AUC from time zero to infinity, $C_{\max }$ maximum observed plasma concentration, $N D$ not determined due to insufficient data, $N R$ not reported, $t_{l a g}$ lag time: time delay between drug administration and onset of drug absorption, $t_{\max }$ time to reach maximum concentration after drug administration, $\% C V$ percent coefficient of variation of geometric mean

${ }^{\mathrm{a}} n=2$

b $n=7$

c Median (range)

d $n=6$

e $n=10$

f $n=3$

g $n=9$

\subsection{Lenvatinib Metabolites}

Plasma concentrations of lenvatinib metabolites were frequently below the lower limit of detection, although there was a trend of increasing levels of metabolites following administration of rifampicin (Table 3). For M1 and M3, levels were undetectable following lenvatinib mesylate administration but were occasionally measurable with rifampicin coadministration. Exposures (geometric mean $C_{\max }$ and $\mathrm{AUC}_{\text {last }}$ ) to $\mathrm{M} 2$ increased following both a single dose (4.30-6.59 times) and multiple doses (2.92-3.11 times) of rifampicin. Similarly, M5 exposure following either a single dose or multiple doses of rifampicin was 1.15-2.62 times greater than after lenvatinib mesylate alone. However, total lenvatinib exposure was 89-710 times greater than exposure of the M2 metabolite and 770-39,487 times greater than exposure of the other three metabolites.

\subsection{Safety}

Seven of the 15 subjects (47\%) reported treatment-emergent AEs (TEAEs). Headache $(n=3,20 \%)$, nausea $(n=3,20 \%)$ and diarrhoea $(n=2,13 \%)$ were the most frequently occurring TEAEs. No serious or significant TEAEs were reported and all TEAEs were either mild or moderate in severity. One subject experienced mild TEAEs (skin rash and oedema) during the rifampicin-only stage of treatment Period 3 (prior to lenvatinib mesylate dosing) leading to withdrawal from the study. Five (33\%) subjects reported treatment-related TEAEs. 
Overall, no treatment-related trends were observed in any safety parameters. Mean vital sign measurements after dosing were similar to those at baseline, and all ECG results were either normal or considered not clinically significant. Mean haematology and clinical chemistry values were within reference ranges, and mean values before each dose of study drug were similar to those at the end of the study. The analyses from normal at baseline to abnormal at study termination revealed no shifts of clinical concern for haematology, clinical chemistry or urinalysis parameters. No abnormal clinical laboratory results were reported as TEAEs.

\section{Discussion}

This single-centre, open-label study conducted in healthy volunteers evaluated the effects of P-gp inhibition (singledose rifampicin) and simultaneous CYP3A4 and P-gp induction (multiple-dose rifampicin) on the pharmacokinetic profile of lenvatinib. The pharmacokinetic profile of single-dose lenvatinib mesylate was generally consistent with previous evaluations of total (protein bound + unbound) lenvatinib pharmacokinetic profile (10-mg single dose) in healthy volunteers, which demonstrated that the median $t_{\max }$ was $2 \mathrm{~h}$ (range $2-4 \mathrm{~h}$ ), mean $t_{1 / 2}$ was $27.6 \mathrm{~h}$ (CV: $27.3 \%$ ), mean $C_{\max }$ was $139.4 \mathrm{ng} / \mathrm{mL}(\mathrm{CV}: 26 \%)$, and $\mathrm{AUC}_{0-\infty}$ was $1,378 \mathrm{ng} \cdot \mathrm{h} / \mathrm{mL}(\mathrm{CV}: 22 \%)$ [24]. With coadministration of a single dose of rifampicin with lenvatinib mesylate, an increase in lenvatinib $\mathrm{AUC}_{0-\infty}$ (free: $+32 \%$; total: $+31 \%$ ) and $C_{\max }$ (free: $+30 \%$; total: $+33 \%$ ) was observed, with corresponding decreases in apparent volume of distribution (free: $-32 \%$; total: $25 \%$ ) and CL/F (free: $-24 \%$; total: $-23 \%$ ).

These data suggest that increased lenvatinib exposure may result from presystemic inhibition of P-gp, since only a minimal change in $t_{1 / 2}$ was observed. In contrast, when $\mathrm{P}$-gp and CYP3A4 were induced, the CIs for the geometric least square means of the $\mathrm{AUC}_{0-\infty}$ and $C_{\max }$ for free lenvatinib were all within the prespecified boundaries for bioequivalence. The lower bound for the $90 \% \mathrm{CI}$ for total lenvatinib $\mathrm{AUC}_{0-\infty}$ was marginally below the prespecified lower bound of equivalence $(80 \%)$ at $73.3 \%$. Systemic exposure to free and total lenvatinib decreased by approximately 9 and $18 \%$, respectively, while $C_{\max }$ increased by $8 \%$ (free lenvatinib) or was unchanged (total lenvatinib). The $<10 \%$ reduction in AUC for lenvatinib when coadministered with multiple doses of rifampicin appears to be related to an increase in systemic metabolic clearance resulting from CYP3A4 induction, since there was also a decrease in $t_{1 / 2}$.

Rifampicin decreases exposure to other TKIs more profoundly. AUC decreases of $68-74 \%$ were reported from a multiple-dosing study of rifampicin with imatinib [17], while decreases of 80,40 and $83 \%$ were reported, respectively, in multiple-dose rifampicin studies of nilotinib [16], vandetanib [25] and gefitinib [18]. Furthermore, while $C_{\max }$ for lenvatinib was essentially unchanged with multiple doses of rifampicin, $C_{\max }$ for other TKIs decreased 54-65\% following administration of imatinib, nilotinib and gefitinib in the presence of rifampicin [1618].

Levels of lenvatinib metabolites increased slightly following administration of rifampicin; however, this is unlikely to alter the pharmacological effect of lenvatinib for two reasons. First, lenvatinib is at least 20-fold more active than its metabolites. Lenvatinib has an half maximal inhibitory concentration $\left(\mathrm{IC}_{50}\right)$ value of $3.4 \mathrm{nmol} / \mathrm{L}(95 \%$ CI $1.4-8.4 \mathrm{nmol} / \mathrm{L})$ against VEGF-driven proliferation of human umbilical vein endothelial cells compared with $\mathrm{IC}_{50}$ values of $57 \mathrm{nmol} / \mathrm{L}$ for $\mathrm{M} 1,250 \mathrm{nmol} / \mathrm{L}$ for $\mathrm{M} 2$ and $230 \mathrm{nmol} / \mathrm{L}$ for M3 (Eisai data on file). In addition, as shown in this study, exposure to lenvatinib is markedly greater than exposure to the metabolites. As such, the net effect of changes in lenvatinib metabolites should have no effect on VEGF-mediated effects.

Safety data from this study indicate that single-dose lenvatinib mesylate (24 mg) had an acceptable safety profile when administered to healthy subjects alone or in combination with single- and multiple-dose rifampicin. There were no clinically significant safety or laboratory changes associated with any of the dosing combinations. Mild or moderate headache and gastrointestinal toxicities were the most common TEAEs.

In conclusion, the results of this study showed that exposure to free lenvatinib in healthy volunteers met the prespecified CIs for bioequivalence when lenvatinib mesylate was given with multiple daily doses of rifampicin. Therefore, no clinically important alterations in lenvatinib exposure are expected following coadministration of lenvatinib mesylate with potent CYP3A4 and $\mathrm{P}$-gp inducers. Although in vitro studies assessing the role of oxidative metabolism found that CYP3A4 was the major CYP involved in lenvatinib metabolism, this in vivo study demonstrated minimal changes in lenvatinib exposure with rifampicin, suggesting that CYP3A4 (and other CYP450)-mediated metabolism appears to be minimally involved in lenvatinib metabolism/total clearance, consistent with results observed in another clinical study with CYP3A4 inhibition using ketoconazole [26].

Acknowledgements Editorial support was provided by Phase Five Communications Inc. and Oxford PharmaGenesis Inc., and was funded by Eisai Inc. All bioanalytical work was performed by WuXi AppTec, Shanghai, P.R. China, on behalf of Eisai. 
Conflicts of interest R. Shumaker, J. Aluri, G. Martinez and M. Ren are employees of Eisai Inc.

G.A. Thompson is a paid consultant to Eisai Inc.

J. Fan is a former employee of Eisai Inc.

Open Access This article is distributed under the terms of the Creative Commons Attribution Noncommercial License which permits any noncommercial use, distribution, and reproduction in any medium, provided the original author(s) and the source are credited.

\section{References}

1. Bergers G, Hanahan D. Modes of resistance to anti-angiogenic therapy. Nat Rev Cancer. 2008;8:592-603.

2. Matsui J, Funahashi Y, Uenaka T, Watanabe T, Tsuruoka A, Asada M. Multi-kinase inhibitor E7080 suppresses lymph node and lung metastases of human mammary breast tumor MDA-MB231 via inhibition of vascular endothelial growth factor-receptor (VEGF-R) 2 and VEGF-R3 kinase. Clin Cancer Res. 2008;14:5459-65.

3. Matsui J, Yamamoto Y, Funahashi Y, Tsuruoka A, Watanabe T, Wakabayashi T, et al. E7080, a novel inhibitor that targets multiple kinases, has potent antitumor activities against stem cell factor producing human small cell lung cancer H146, based on angiogenesis inhibition. Int J Cancer. 2008;122:664-71.

4. Boss DS, Glen H, Beijnen JH, Keesen M, Morrison R, Tait B, et al. A phase I study of E7080, a multitargeted tyrosine kinase inhibitor, in patients with advanced solid tumours. Br J Cancer. 2012;106:1598-604.

5. Yamada K, Yamamoto N, Yamada Y, Nokihara H, Fujiwara Y, Hirata $\mathrm{T}$, et al. Phase I dose-escalation study and biomarker analysis of E7080 in patients with advanced solid tumors. Clin Cancer Res. 2011;17:2528-37.

6. Sherman SI, Jarzab B, Cabanillas ME, Licitra LF, Pacini F, Martins R, et al. A phase II trial of the multitargeted kinase inhibitor E7080 in advanced radioiodine (RAI)-refractory differentiated thyroid cancer (DTC) [abstract]. J Clin Oncol. 2011;29(15 Suppl). Abstract 5503.

7. Shumaker R, Fan J, Martinez G, Chen K. Comparative bioavailability study of a 10-mg capsule and a 10-mg tablet of lenvatinib (E7080) in health subjects [abstract]. Clin Pharmacol Ther. 2012;91(Suppl 1):S68. Abstract PII-46.

8. Dubbelman AC, Rosing H, Mergui-Roelvink M, Gupta A, Verbel $\mathrm{D}$, Sellecchia R, et al. A mass balance study of ${ }^{14} \mathrm{C}$-lenvatinib (E7080) in patients with advanced solid tumours or lymphomas [abstract]. Br J Clin Pharmacol. 2013;76:831.

9. Inoue K, Asai N, Mizuo H, Fukuda K, Kusano K, Yoshimura T. Unique metabolic pathway of $\left[{ }^{14} \mathrm{C}\right]$ lenvatinib after oral administration to male cynomolgus monkey. Drug Metab Dispos. 2012;40:662-70.

10. Reitman ML, Chu X, Cai X, Yabut J, Venkatasubramanian R, Zajic S, et al. Rifampin's acute inhibitory and chronic inductive drug interactions: experimental and model-based approaches to drug-drug interaction trial design. Clin Pharmacol Ther. 2011;89:234-42.

11. Chen J, Raymond K. Roles of rifampicin in drug-drug interactions: underlying molecular mechanisms involving the nuclear pregnane X receptor. Ann Clin Microbiol Antimicrob. 2006;5:3.
12. Niemi M, Backman JT, Fromm MF, Neuvonen PJ, Kivistö KT. Pharmacokinetic interactions with rifampicin: clinical relevance. Clin Pharmacokinet. 2003;42:819-50.

13. Dresser GK, Spence JD, Bailey DG. Pharmacokinetic-pharmacodynamic consequences and clinical relevance of cytochrome P450 3A4 inhibition. Clin Pharmacokinet. 2000;38:41-57.

14. Bjornsson TD, Callaghan JT, Einolf HJ, Fischer V, Gan L, Grimm S, et al. The conduct of in vitro and in vivo drug-drug interaction studies: a PhRMA perspective. J Clin Pharmacol. 2003;43:443-69.

15. US Department of Health and Human Services, Food and Drug Administration, Center for Drug Evaluation and Research (CDER). Guidance for industry: drug interaction studies-study design, data analysis, implications for dosing, and labeling recommendations. 2012. http://www.fda.gov/downloads/Drugs/ GuidanceComplianceRegulatoryInformation/Guidances/ucm292 362.pdf. Accessed 14 Jan 2014.

16. Tanaka C, Yin OQ, Smith T, Sethuraman V, Grouss K, Galitz L, et al. Effects of rifampin and ketoconazole on the pharmacokinetics of nilotinib in healthy participants. J Clin Pharmacol. 2011;51:75-83.

17. Bolton AE, Peng B, Hubert M, Krebs-Brown A, Capdeville R, Keller U, et al. Effect of rifampicin on the pharmacokinetics of imatinib mesylate (Gleevec, STI571) in healthy subjects. Cancer Chemother Pharmacol. 2004;53:102-6.

18. Swaisland HC, Ranson M, Smith RP, Leadbetter J, Laight A, McKillop D, et al. Pharmacokinetic drug interactions of gefitinib with rifampicin, itraconazole and metoprolol. Clin Pharmacokinet. 2005;44:1067-81.

19. Dickinson BD, Altman RD, Nielsen NH, Sterling ML, Council on Scientific Affairs, American Medical Association. Drug interactions between oral contraceptives and antibiotics. Obstet Gynecol. 2001;98:853-60.

20. Dubbelman AC, Rosing H, Thijssen B, Gebretensae A, Lucas L, Chen H, et al. Development and validation of LC-MS/MS assays for the quantification of E7080 and metabolites in various human biological matrices. J Chromatogr B Analyt Technol Biomed Life Sci. 2012;887-888:25-34.

21. Gibaldi M, Perrier D. Pharmacokinetics. New York: Marcel Dekker, Inc.; 1975.

22. Jusko WJ. Guidelines for collection and analysis of pharmacokinetic data. In: Evans WE, Schentag JJ, Jusko WJ, editors. Applied pharmacokinetics: principles of therapeutic drug monitoring. 3rd ed. Vancouver, WA: Applied Therapeutics, Inc.; 1992. p. 1-43.

23. Schuirmann DJ. A comparison of the two one-sided tests procedure and the power approach for assessing the equivalence of average bioavailability. J Pharmacokinet Biopharm. 1987;15:657-80.

24. Shumaker R, Aluri J, Fan J, Martinez G, Ren M, Chen K. Evaluation of the effects of formulation and food on the pharmacokinetics of lenvatinib (E7080) in healthy volunteers. Int J Clin Pharmacol Ther. 2014;52:284-91.

25. Martin P, Oliver S, Robertson J, Kennedy SJ, Read J, Duvauchelle T. Pharmacokinetic drug interactions with vandetanib during coadministration with rifampicin or itraconazole. Drugs $\mathrm{R}$ D. 2011;11:37-51.

26. Shumaker R, Aluri J, Fan J, Martinez G, Thompson GA, Ren M. Effect of ketoconazole coadministration on lenvatinib (E7080) exposure in healthy volunteers. Poster presented at: 24th EORTC-NCI-AACR Symposium on Molecular Targets and Cancer Therapeutics, November 6-9, 2012, Dublin, Ireland. 